\title{
Corrigendum
}

\section{Quantitative analyses of the abundance and composition of ammonia-oxidizing bacteria and ammonia-oxidizing archaea of a Chinese upland red soil under long-term fertilization practices}

\author{
Ji-zheng He, ${ }^{1 * \dagger}$ Ju-pei Shen, ${ }^{1,2 \dagger}$ Li-mei Zhang, ${ }^{1 \dagger}$ Yong-guan Zhu, ${ }^{1}$ Yuan-ming Zheng, ${ }^{1} \mathrm{Ming}^{-g a n g} \mathrm{Xu}^{3}$ and \\ Hongjie $\mathrm{Di}^{4}$ \\ ${ }^{1}$ State Key Laboratory of Urban and Regional Ecology, Research Centre for Eco-environmental Sciences, \\ Chinese Academy of Sciences, Beijing 100085, China. \\ ${ }^{2}$ Graduate School, Chinese Academy of Sciences, Beijing 100039, China. \\ ${ }^{3}$ Institute of Soil and Fertilizer, Chinese Academy of Agricultural Sciences, Beijing 100081, China. \\ ${ }^{4}$ Agriculture and Life Sciences Division, PO Box 84, Lincoln University, Canterbury, New Zealand.
}

In the article 'Quantitative analyses of the abundance and composition of ammonia-oxidizing bacteria and ammoniaoxidizing archaea of a Chinese upland red soil under long-term fertilization practices' (He et al., 2007), some mistakes were found in Table 3. The correct table is on the following page:

Table 3. Primers, probes and PCR conditions used for the real-time PCR.

\begin{tabular}{|c|c|c|c|c|c|c|}
\hline Target group & Primer and probe & $\begin{array}{l}\text { Sequence } \\
\left(5^{\prime}-3^{\prime}\right)\end{array}$ & $\begin{array}{l}\text { Length } \\
\text { (bp) }\end{array}$ & $\begin{array}{l}\text { Concentration } \\
\text { (nM) }\end{array}$ & Thermal profile & Reference \\
\hline \multirow[t]{3}{*}{ AOB } & Primer A189 & GGHGACTGGGAYTTCTGG & 670 & 100 & $\begin{array}{l}15 \text { min at } 95^{\circ} \mathrm{C} \text {, followed by } \\
40 \text { cycles of } 60 \mathrm{~s} \text { at } 94^{\circ} \mathrm{C}, \\
45 \mathrm{~s} \text { at } 57^{\circ} \mathrm{C} \text { and } 45 \mathrm{~s} \text { at } \\
72^{\circ} \mathrm{C}\end{array}$ & $\begin{array}{l}\text { Okano } \\
\text { et al. } \\
\text { (2004) }\end{array}$ \\
\hline & Primer amoA-2R' & CCTCKGSAAAGCCTTCTTC & & 100 & & \\
\hline & Probe $\mathrm{A} 337$ & $\begin{array}{l}\text { TTCTACTGGTGGTCRCACT } \\
\text { ACCCCATCAACT }\end{array}$ & & 120 & & \\
\hline \multirow[t]{3}{*}{ Bacteria } & Primer BACT1369F & CGGTGAATACGTTCYCGG & 172 & 1000 & $\begin{array}{l}10 \mathrm{~s} \text { at } 95^{\circ} \mathrm{C}, \text { followed by } 35 \\
\text { cycles of } 15 \mathrm{~s} \text { at } 95^{\circ} \mathrm{C}, \\
1 \mathrm{~min} \text { at } 56^{\circ} \mathrm{C}\end{array}$ & $\begin{array}{l}\text { Suzuki } \\
\text { et al. } \\
\text { (2000) }\end{array}$ \\
\hline & Primer PROK1541R & AAGGAGGTGATCCRGCCGCA & & 500 & & \\
\hline & Probe TM1389F & CTTGTACACACCGCCCGTC & & 500 & & \\
\hline \multirow[t]{2}{*}{$\mathrm{AOA}$} & Primer Arch-amoAF & STAATGGTCTGGCTTAGACG & 635 & 100 & $\begin{array}{c}94^{\circ} \mathrm{C} \text { for } 2 \text { min followed by } \\
40 \text { cycles of } 45 \mathrm{~s} \text { at } 94^{\circ} \mathrm{C}, \\
1 \mathrm{~min} \text { at } 53^{\circ} \mathrm{C}, 45 \mathrm{~s} \text { at } \\
68^{\circ} \mathrm{C} \text {, plate read at } 83^{\circ} \mathrm{C} \text {. }\end{array}$ & $\begin{array}{l}\text { Francis } \\
\quad \text { et al. } \\
\text { (2005) }\end{array}$ \\
\hline & Primer Arch-amoAR & GCGGCCATCCATCTGTATGT & & 100 & & \\
\hline
\end{tabular}

We apologize for this error.

\section{Reference}

He, J.-Z., Shen, J.-P., Zhang, L.-M., Zhu, Y.-G., Zheng, Y.-M., Xu, M.-G., and Di, H. (2007) Quantitative analyses of the abundance and composition of ammonia-oxidizing bacteria and ammonia-oxidizing archaea of a Chinese upland red soil under lonlg-term fertilization practices. Environ Microbiol 9: 2364-2374. 